\title{
HAZARDS OF RADIATION
}

\begin{abstract}
HE committee on radiological hazards to patients, with Lord Adrian as chairman, has now published its second report*. The first, an interim leport dealing only with mass miniature radiography, was issued in 1956 and has been reviewed previously (Nature, 178, 453; 1956). The present report is devoted to considerations of the long-term genetic hazard to the population as a whole arising from the average radiation-dose received by the population in excess of that from natural sources. The statistical nature of the investigation and of its results is stressed; although doubling the average dose of $3 \mathrm{r}$. to the gonads during reproductive life might give reason for concern from a genetical point of view, a gonad-dose of $6 \mathrm{r}$. received by a single individual is not likely to cause abnormalities in the immediate progeny.

The conclusions of the committee are based on two nation-wide surveys. During one week in May 1957, a survey was made in Britain of the numbers and types of X-ray examinations carried out, of the number of films used, and of the apparatus available in all National Health Service hospitals and chest clinics, in dental surgeries and in a few other institutions. Including fluoroscopic examinations, this survey covered a total of 259,457 radiological examinations. The second survey, during one week in December 1957, was made in a random selection of about one quarter of the National Health Service hospitals and chest clinics, and totalled 55,065 radiological examinations. These surveys were supplemented by physical measurements (totalling about 14,000) of the radiation-dose received by patients undergoing different types of radiological procedures in a representative sample of 130 hospitals and chest clinics.

When account is taken of seasonal differences in the frequency of examinations, the data from both surveys agree in indicating a total of 13.0 million radiological examinations during 1957. This is somewhat more than the corresponding figure of $12 \cdot 2$ million used in the Medical Research Council's first report. In large part this may be due to the much more restricted sample that was available for the earlier estimate. More important, and possibly an indication that the recommendations of 1956 had

- Medical Research Councll. The Hazards to Man of Nuclear and Allied Radiutions-a Second Report to the Medical Research Council (Cmnd. 1225.) Pp. vii +154. (London : H.M. Stationery Office, 1960.) 78 .
\end{abstract}

already influenced radiological practice in 1957, was a difference in age distribution of patients examined in the two reports. While in 1956 it had been estimated that 31.9 per cent of all examinations had been given to the age group $0-14$, and $25 \cdot 9$ per cent to the overfifty age group, the corresponding figures in 1957 were 13.5 and $34 \cdot 4$ per cent. From a genetical point of view, this is a desirable development; for the potential effect of a given dose on future generations is greater in a young person having a high expectancy of parenthood than in an older person. In fact, the calculations of genetical hazards in the present report make use of fertility factors giving the average child expectancy at each age for arriving at the "genetic dose to the population". By this is meant the gonad. dose which, if given to every member of the population, would have the same effect as the sum of the individual doses actually received.

The results of the surveys are expressed as $\mathrm{mr}$. (milliroentgens) annual genetic dose per head of the population. All medical radiology in 1957/58, both diagnostic and therapeutic, resulted in a genetic dose of $19.3 \mathrm{mr}$. This is less than the figure for diagnostic radiology alone $(22 \mathrm{mr}$.) in the Medical Research Council's report of 1956 . The main contributions to the total of $19.3 \mathrm{mr}$. are: diagnostic radiology $14.1 \mathrm{mr}$., radiotherapy of non-malignant conditions $4.5 \mathrm{mr}$, radiotherapy of malignant conditions $0.5 \mathrm{mr}$. ; minor contributions are made by medical uses of radioactive isotopes $(0.18 \mathrm{mr}$.), mass miniature radiography $(0.01 \mathrm{mr}$.) and dental radiography $(0.01 \mathrm{mr}$.$) . The dose to the gonads from any \mathrm{X}$-ray examination is small in comparison with that con. sidered by the Medical Research Council to be acceptable to the individual without causing undue concern on behalf of himself or his offspring. The committee therefore concludes that there is no need for major restrictions in radiological practice, and that the number and types of examinations or treatments must be dictated by the clinical needs of the patient. Nevertheless, it considers that, whenever possible, the gonad-dose should be reduced even further, and it gives detailed recommendations how this can be done, especially in the case of pregnant women. It is satisfied that, if these recommendations are followed, the total annual genetic dose to the population from all forms of medical radiology can be reduced to a figure of $6 \mathrm{mr}$. or less. C. AUERBACH

\section{PHYSIOLOGY OF SUGAR-CANE}

$\mathrm{R}$ L. BIELESKI (A ustralian J. Biol. Sci., 13, 203 ; 1960) has found that the sugar uptake by sugarcane storage tissue takes place in two stages. In experiments in which slices of mature and immature storage tissue were used, the initial uptake reached an equilibrium within $1 \mathrm{hr}$., the level being proportional to the external sugar concentration: it was inde. pendent of the sugar, and was unaffected by anaerobic conditions. When the tissue was placed in water, this sugar diffused out rapidly, that is, it was contained in the apparent free space, 10-20 per cent of the tissue volume. The secondary uptake continued up to $60 \mathrm{hr}$. at a slow, constant rate, 1-5 mgm./gm./day, independent of sugar concentration above 2.0 per cent, dependent on the sugar, and inhibited by anaerobic conditions. This sugar did not diffuse out when the tissue was placed in water. The secondary uptake thus appears to involve an active accumulation process. The sucrose content of the tissue increased during accumulation, which occurred against a 10 - to 200 -fold concentration gradient. There was no starch synthesis, but accumulation was associated with a 30-40 per 